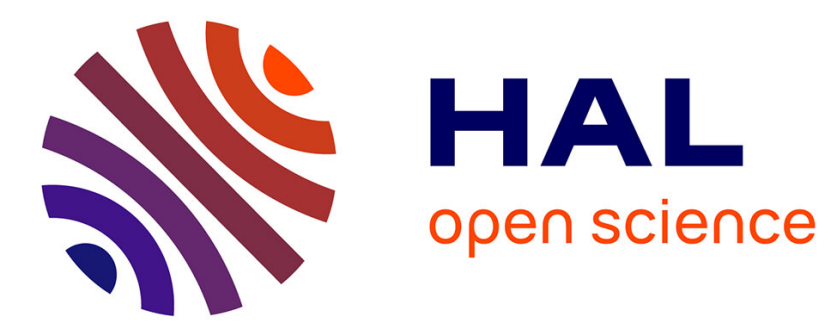

\title{
Improving the power line communication signal-to-noise ratio during a resistive load commutation
}

V. Guillet, Guy Lamarque, Philippe Ravier, Christophe Léger

\section{To cite this version:}

V. Guillet, Guy Lamarque, Philippe Ravier, Christophe Léger. Improving the power line communication signal-to-noise ratio during a resistive load commutation. journal of communications, 2007, 4 (3), pp.126-132. hal-00607873

\section{HAL Id: hal-00607873 https://hal.science/hal-00607873}

Submitted on 11 Jul 2011

HAL is a multi-disciplinary open access archive for the deposit and dissemination of scientific research documents, whether they are published or not. The documents may come from teaching and research institutions in France or abroad, or from public or private research centers.
L'archive ouverte pluridisciplinaire HAL, est destinée au dépôt et à la diffusion de documents scientifiques de niveau recherche, publiés ou non, émanant des établissements d'enseignement et de recherche français ou étrangers, des laboratoires publics ou privés. 


\title{
Improving the power line communication signal-to-noise ratio during a resistive load commutation
}

\author{
V. Guillet, G. Lamarque, P. Ravier and C. Léger, \\ Prisme Institute, University of Orléans, Orléans, France \\ Email: \{vincent.guillet, guy.lamarque, philippe.ravier, christophe.leger\}@univ-orleans.fr
}

\begin{abstract}
In any cable or power line communications, impulse noise is known to be the most difficult noise to filter. In particular, non periodic asynchronous impulse noise is impossible to predict. Under such noise conditions, the OFDM $^{1}$ symbol generally used in PLC $^{2}$ is corrupted. To overcome this problem, the signal-to-noise ratio is generally improved by detecting and/or filtering the noise. This leads however to heavy detection and computing time in comparison with the disturbance duration. In this paper, we study the parameters of the noise generated by a load commutation and propose a new approach that consists in controlling the commutation instant of the load. This approach reduces by up to $15 \mathrm{~dB}$ the asynchronous impulsive noise emitted by a resistive load in a 40.96- $\mu$ s typical Homeplug $\mathrm{AV}^{3}$ OFDM symbol duration. Synchronisation is integrated in electronic commutation system. Results show that the load value does not influence the magnitude of the impulse noise.
\end{abstract}

Index Terms-Commutation, impulse noise, Signal-to-Noise Ratio (SNR) improvement, zero-crossing.

\section{INTRODUCTION}

Wireless communication has become increasingly common, particularly in portable systems. However, when the systems require a power supply, power line communication appears to be a good alternative solution. This communication channel requires no additional wiring, making it effortless and cheap to set up a network in existing buildings. Moreover, it offers Triple Play facilities (Internet, VoIP, Multimedia) thanks to a high $\mathrm{PHY}^{4}$ bit rate, in the range of a few hundred Mbps (Mega bits per second) raw data, and can operate over a distance of around one hundred meters. Achieving such a high bit rate involves optimizing allocation of the authorized bandwidth. An appropriate modulation such as OFDM ${ }^{1}$, which has a good spectral efficiency, enables the overall bandwidth to be taken into account [1]. Nevertheless, it is also very important to have precise knowledge of the topology of the communication channel [2] [3], and the associated noise sources [4].

\footnotetext{
This paper is based on "Reduction of the impulsive noise emitted by a resistive load commutation," by V. Guillet, G. Lamarque, P. Ravier and C. Léger, which appeared in the Proceedings of the 12th IEEE Int. Symposium on Power Line Communications and Its Applications (ISPLC), Jeju Island, Korea, April 2008. (c) 2008 IEEE.

${ }^{1}$ OFDM: Orthogonal Frequency Division Multiplexing.

${ }^{2}$ PLC: Power Line Communication.

${ }^{3}$ Homeplug AV: PLC protocol from homeplug consortium for Audio and Video.

${ }^{4} \mathrm{PHY}$ : Lowest layer in the ISO model network communication.
}

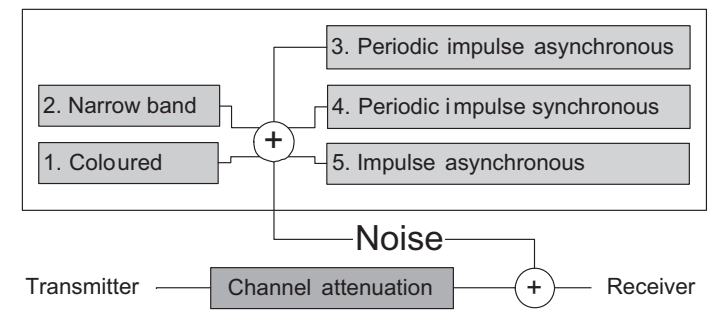

Figure 1. Power line channel noise description.

It is well known that in the power line channel, the noise does not agree with the classical Additive White Gaussian Noise (AWGN) model [4]. The model in figure 1, presented in [4], is therefore generally preferred. In this model, the communication channel is mainly disturbed by a set of five noise sources.

The background noise sources [5] (narrow band and coloured noise) are frequency localized. Conversely, the impulse noise sources [6], [7] are time concentrated. In the latter class, some are periodic (periodic synchronous/asynchronous impulse noise) while the others are not (asynchronous impulse noise).

Among all the types of noise, the asynchronous impulse one is probably the most difficult to deal with. Numerous methods have been developed to detect and/or filter such noise. In instance, for noise sources synchronized to mains [8], periodic and predictive [9] or detected into OFDM subchannels [10], the Signal-to-Noise Ratio will be reduced.

In terms of topology, two elements need to be taken into account: the cable model and connected loads [11]. Generally, rigid cable is used for fixed installations because it is cheaper than a flexible (multi-wire) one, which is preferably used for extensions due to its ease of installation. As the power line channel is limited to fixed installations, only rigid cables wil be considered here. In order to improve the PLC Signal-to-Noise Ratio (SNR) during a resistive load commutation, we have studied the influence of the cable length. The second element of the channel is the load. Among existing loads, we focus on the most elementary ones, namely heaters. Three aspects of the loads are examined: the commutation instant, the nature of the commutation system and the electrical load value. 
The paper is organized as follows. Section II introduces the commutation system and the method used to analyze the noise emitted. Section III presents the results of the commutation of a simple resistive $500 \mathrm{~W}$ mechanical radiator for three different commutation instants $(0 \%$, $50 \%$ and $100 \%$ of the main amplitude). Section IV shows the effect of the line length and its consequences on the bandwidth. The mechanical commutation technology (relay) is compared with the electronic one (triac) in section V. Finally, section VI presents the effect of the commutated load value using an electronic commutation which will be shown to be the least noisy technology.

\section{MATERIALS AND METHODS}

In this study, the commutation effects of a load are analyzed using the schematic presented in figure 2 and described in the following paragraphs.

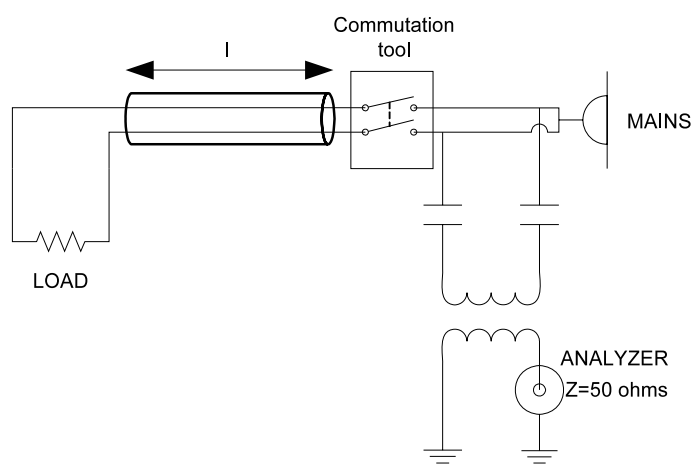

Figure 2. Analysis of the commutation effects.

\section{A. The cable}

In-house installed cables do not use a global shield for the two or three copper conductors, but use corrugated pipes. In this study, a $3 \mathrm{G}$ cable (See Table I) for industrial and tertiary sector buildings is used. This cable is composed of a global shield, making the inter-conductor distance constant.

TABLE I.

CABLE USED FOR THE TEST.

\begin{tabular}{|c|c|}
\hline Conductor type & Solid \\
\hline Manufacturer & La Triveneta Cavi \\
\hline Reference & U1000 R2V \\
\hline Class & PR / Solid \\
\hline $\begin{array}{c}\text { Insulation } \\
\text { (inner / outer ) }\end{array}$ & $3.18 / 2.25$ (Farad/meter) \\
\hline $\begin{array}{c}\text { Approximated permittivity } \\
\text { (inner / outer) }\end{array}$ & \\
\hline
\end{tabular}

\section{B. The load and the commutation}

The load consists in a $240 \mathrm{~V} / 500 \mathrm{~W}$ radiator placed at the end of the cable. This type of load is purely resistive. Its commutation is done using a relay technology, which is equivalent to the thermal switch used in a radiator thermostat. A digital dephasing system synchronised to

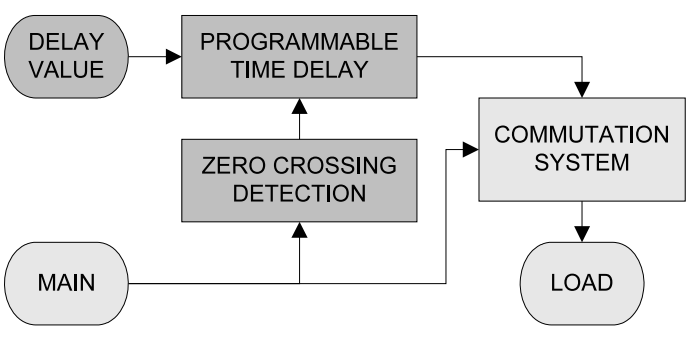

Figure 3. Commutation tool.

the mains voltage is used to determine the relevant commutation instant (Fig. 3).

The zero-crossing circuit detects the instant of a zero amplitude value of the mains power supply. Detection is carried out using an optocoupler [12]. At this precise instant, a digital counter implemented in a $\mathrm{CPLD}^{5}$ (Xilinx CoolRunner II [13]) starts counting. A $100 \mathrm{kHz}$ system clock increments the counter value with a precision of $\mathrm{t} \approx 10 \mu \mathrm{s}$ on the commutation instant. When the delay value is reached, the desired state of the commutation takes effect.

\section{Signal acquisition and processing}

The analysis of the channel is carried out using a standard capacitive coupling circuit. The circuit is designed to reject low frequencies $(50 \mathrm{~Hz})$, carried by the mains power supply, but to let high frequencies pass through. The bandwidth is in the range of $100 \mathrm{kHz}$ to $100 \mathrm{MHz}$. The analyzer is a dual input acquisition board GAGE CompuScope 12400 [14], with 12 bits resolution, and a fixed sampling rate of $200 \mathrm{MHz}$. Due to such a high data flow, the on-board memory avoids the loss of samples during acquisition. A $40 d B$ attenuator is used to limit saturation of the acquisition tool. The input impedance of this attenuator is $50 \Omega$. Signal processing is carried out using a MATLAB environment in diferred time. The measurement includes an overvoltage protection using a sufficient bandwidth to ensure correct analysis.

In order to reduce the random part of the commutation signal and the contact bounce, ten acquisition sequences are carried out for each parameter (cable length and dephasing value).

\section{Mechanical thermostat Radiator BehaVior}

The observed time duration of commutation pulses is from $1 \mu \mathrm{s}$ to $50 \mu \mathrm{s}$. In a few cases, some bounce can be observed (see figure 4). This is due to the relay technology used by the commutation system. However, such bouncing can also be observed in a thermal switch commutation employed in radiator thermostats.

A time-frequency analysis is carried out using ShortTime Fourier Transform (STFT) (Fig. 4). The square modulus of the STFT also called spectrogram is estimated using 1024-points rectangular windows (corresponding to about $5 \mu$ s window duration). The 1024-points Fast

\footnotetext{
${ }^{5}$ CPLD: Complex Programmable Logic Device.
} 
Fourier Transform (FFT) spectra are evaluated on sliding windows with $95 \%$ overlap between the slices.
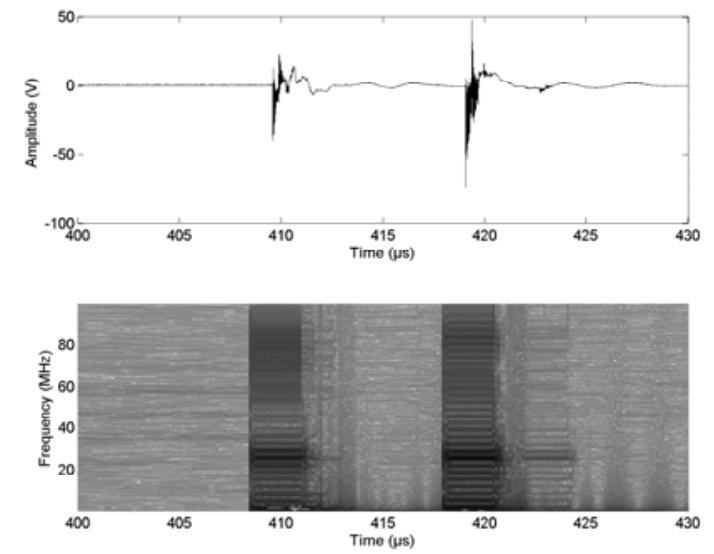

Figure 4. Time frequency analysis of a commutation.

The time frequency diagram (Fig. 4) clearly demonstrates that during the full pulse duration time, all frequencies, including the authorized PLC bandwidth, are affected. Moreover, the disturbance duration (from $2 \mu \mathrm{s}$ to $20 \mu \mathrm{s}$ ) is of the same order as the OFDM symbol duration of PLC standard protocols (from $10 \mu \mathrm{s}$ to $100 \mu \mathrm{s}$ ). This shows that the disturbance time and the detection/processing time are equivalent, meaning that detecting pulses is not efficient. We therefore propose a new approach to control the commutation instant, in order to reduce the noise.

Fig. 5 presents the noise PSD (Power Spectrum Density) obtained using a Welch periodogram over 2048 samples with a rectangular window and without any overlap in a 40.96- $\mu$ s typical Homeplug AV OFDM symbol duration. The time delay is set at 0,8 and 25 percent of the power supply period, corresponding respectively to a load commutation when the power supply sinusoidal amplitude is equal to $0 \%, 50 \%$ and $100 \%$ of the maximum voltage value. A 30-meter cable is used in this comparison.

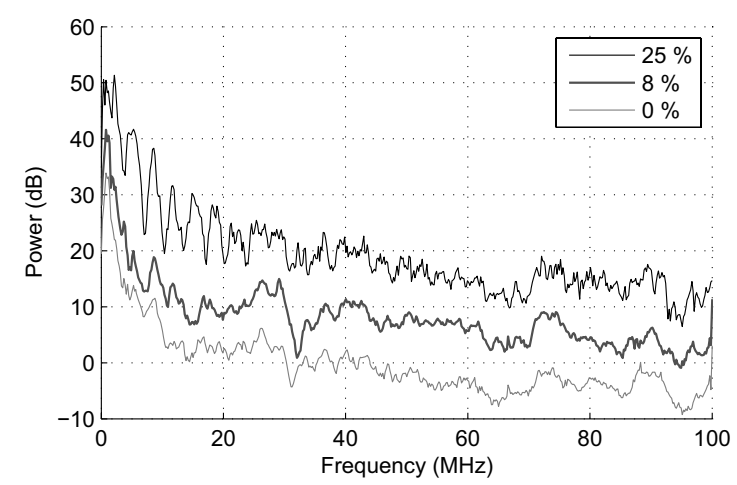

Figure 5. Comparison of the PSD waveforms as a function of three commutation instants for a 30 -meter cable.

Fig. 5 shows that the noise floor increases as a function of the delay of the commutation. The disturbance duration is measured from 2 to 3 OFDM-symbols in the worth case, but without commutation bounces.
In order to easily estimate the SNR improvement, an approximation model of the background noise is used (Equation 1, [15]).

$$
P(f)=a-b \cdot f^{c}(d B / M H z)
$$

The fitting curves are presented in figure 6 . The $a, b$ and $c$ parameters are given in table II.

TABLE II.

FITTING CURVES PARAMETERS FOR A 30-METER CABLE.

\begin{tabular}{|c|c|c|c|c|}
\hline $\begin{array}{c}\text { Commutation } \\
\text { instant }\end{array}$ & $\begin{array}{c}\text { Switched } \\
\text { Amplitude }\end{array}$ & $\mathrm{a}$ & $\mathrm{b}$ & $\mathrm{c}$ \\
\hline $0 \%$ & $0 \%$ & $-13,9$ & 45,9 & $-0,3$ \\
\hline $8 \%$ & $50 \%$ & $-0,3$ & 39,9 & $-0,5$ \\
\hline $25 \%$ & $100 \%$ & $-31,3$ & 83,8 & $-0,1$ \\
\hline
\end{tabular}

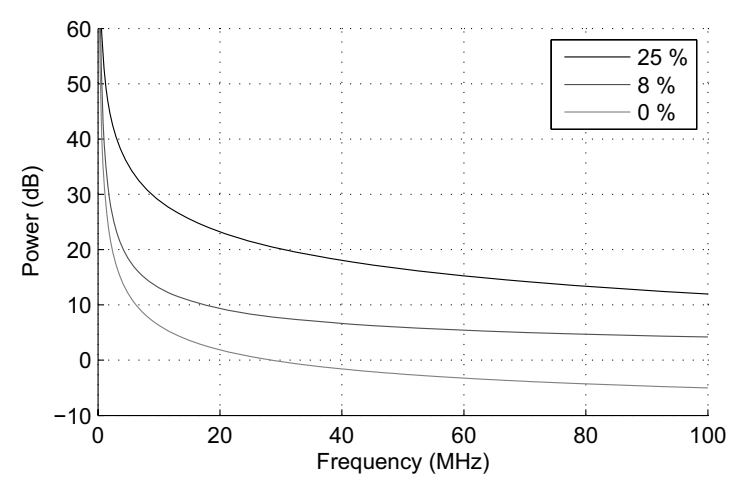

Figure 6. Fitting curves with respect to the background noise model for a 30 -meter cable.

It can clearly be seen from Fig. 6 that the noise power is lies between the noise level given by the curves at $0 \%$ and $25 \%$ commutation instant. Controlling the commutation instant limits the noise floor to its lower value. In this way, the SNR can be improved by about $15 \mathrm{~dB}$ in a $40.96-\mu$ s typical OFDM symbol duration. This improvement is enhanced by other considerations: fixing the time-synchronisation to the zero-amplitudevoltage instant $\left(t_{z c i}\right)$ of the mains power will reduce the step sollicitation to the commutation system and also to the load. Consequently, the breaking capacity will be preserved and the dissipated power reduced.

\section{INFLUENCE OF THE CABLE LENGTH}

In order to assess the independence of the cable length, the experimentation was also carried out with a 70-meter cable. The PSDs obtained are presented in figure 7. Figure 8 presents the fitting results.

The PSD and the fitting curves are estimated in the same manner as in section III. Table III gives the parameters obtained for the fitting.

The fitting curves (Fig. 6 and Fig. 8) obtained for a 30meter and a 70-meter cables show similar behaviour for a given commutation instant. Consequently, controlling the commutation instant may indeed reduce the SNR by about $15 \mathrm{~dB}$, irrespective of the cable length. 


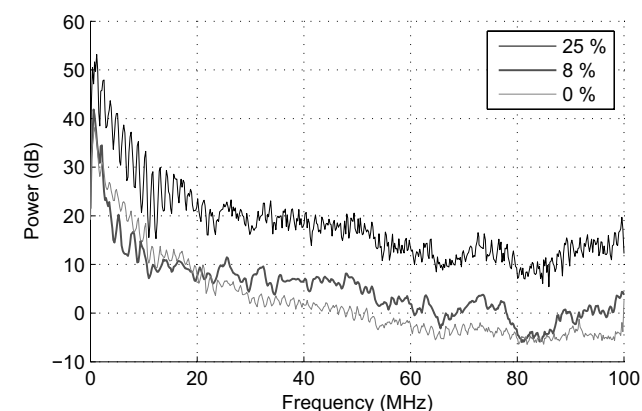

Figure 7. Comparison of the PSD waveforms for a 70-meter cable.

TABLE III

FITTING CURVES PARAMETERS FOR A 70-METER CABLE.

\begin{tabular}{|c|c|c|c|c|}
\hline $\begin{array}{c}\text { Commutation } \\
\text { instant }\end{array}$ & $\begin{array}{c}\text { Switched } \\
\text { Amplitude }\end{array}$ & $\mathrm{a}$ & $\mathrm{b}$ & $\mathrm{c}$ \\
\hline $0 \%$ & $0 \%$ & -209 & 246 & $-0,04$ \\
\hline $8 \%$ & $50 \%$ & -100 & 127 & $-0,05$ \\
\hline $25 \%$ & $100 \%$ & $-31,6$ & 84,8 & $-0,15$ \\
\hline
\end{tabular}

In fig. 5 and 7 , ripples are visible. Their frequencies appear to increase with cable length. The ripple might be related to the line characteristic impedance mismatch. In order to verify this hypothesis, a cable analysis was performed, using the same analysis circuit, but replacing the load by a generator and leaving the commutation switch closed (Fig. 9). The generator is an arbitrary waveform generator (GAGE CompuGen 4300 [16]) using a white noise sampled at the frequency of $300 \mathrm{MHz}$. The output of the generator matches the full scale input of a line driver (OPA2674, [17]) avoiding saturation. Another coupling circuit is added on the line driver output.

The results for a 30-meter, 50-meter and 70-meter cable are presented in fig. 10.

The line impedance mismatch will produce reflections over the line. These reflected signals will be added to the measured signal after a propagation time given by equation 2 :

$$
t_{p}=\frac{l}{v_{p}}=\frac{l}{\frac{C}{\sqrt{\epsilon_{r}}}}, \text { using } v_{p}=\frac{C}{\sqrt{\epsilon_{r}}}
$$

where $l$ is the length of the cable, $v_{p}$ is the propagation speed, $C \approx 3.10^{8} \mathrm{~m} / \mathrm{s}$ is the light speed in vacuum and $\epsilon_{r}$ is the permittivity of the dielectric.

During a propagation time $t_{p}$, it is possible to observe a $k$ number of a $\frac{1}{f}$ sinusoidal signal period.

$$
t_{p}=k * \frac{1}{f}
$$

A maximum value is obtained in $f_{k}$ for each integer value of $k$ :

$$
f_{k}=\frac{k}{t_{p}}
$$

Moreover, the frequency distance between two local maxima is $\Delta F$ :

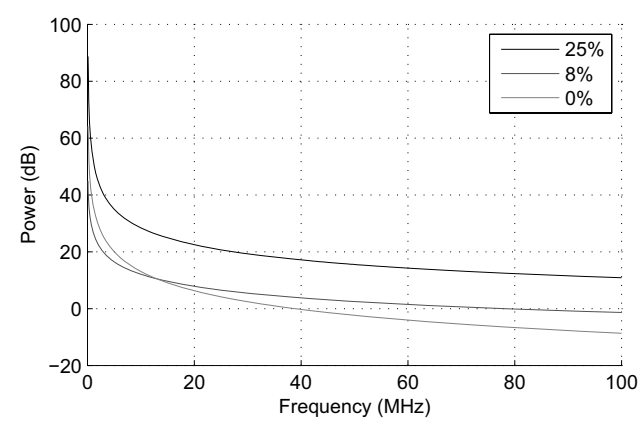

Figure 8. Fitting curves with respect to the background noise model for a 70 -meter cable.

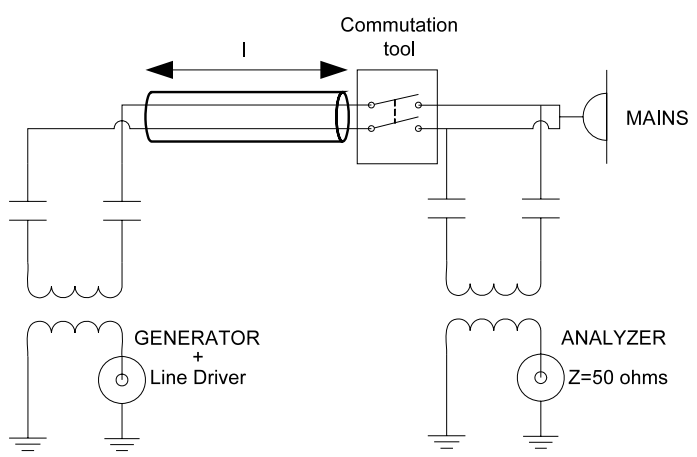

Figure 9. Method to analyze the bandwidth of the cable.

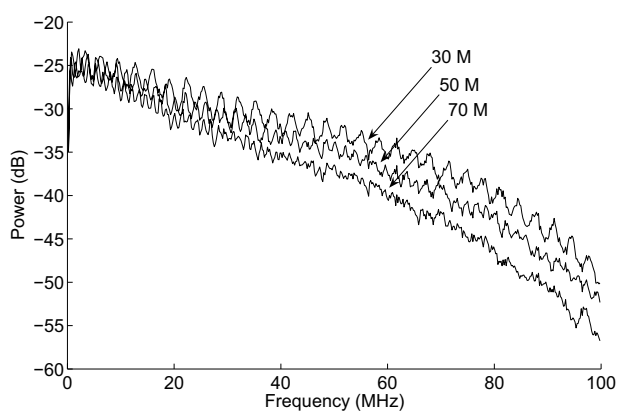

Figure 10. Ripples in the bandwidth.

$$
\Delta F=f_{k+1}-f_{k}=\frac{k+1}{t_{p}}-\frac{k}{t_{p}}=\frac{1}{t_{p}}
$$

The measurement enables the cable propagation time and the cable dielectric permittivity to be evaluated using equation (2):

$$
\frac{1}{\Delta F}=t_{p}=0.52 \mu s, \sqrt{\epsilon_{r}}=\frac{C}{\frac{l}{t_{p}}}, \epsilon_{r} \approx 3.12
$$

The frequency ripple value (the distance between two local maxima, $\Delta F)$ for different cable lengths $(1,20,30$, $50,70,78$ meters) is measured using zooms such as those shown on fig. 11.

Ripple measurements are reported in figure 12, where equation (2) is also plotted. The two curves are superimposed, demonstrating that the ripples are due to the 


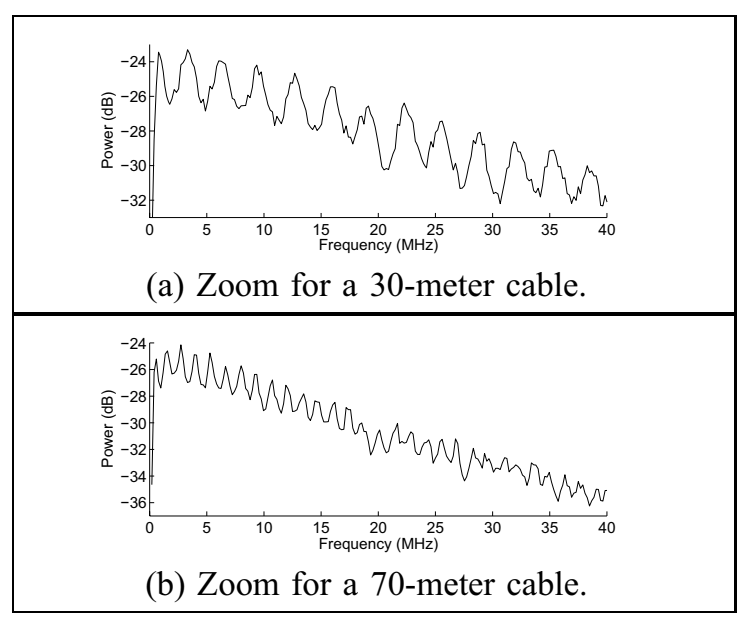

Figure 11. Zoom on ripples in the bandwidth.

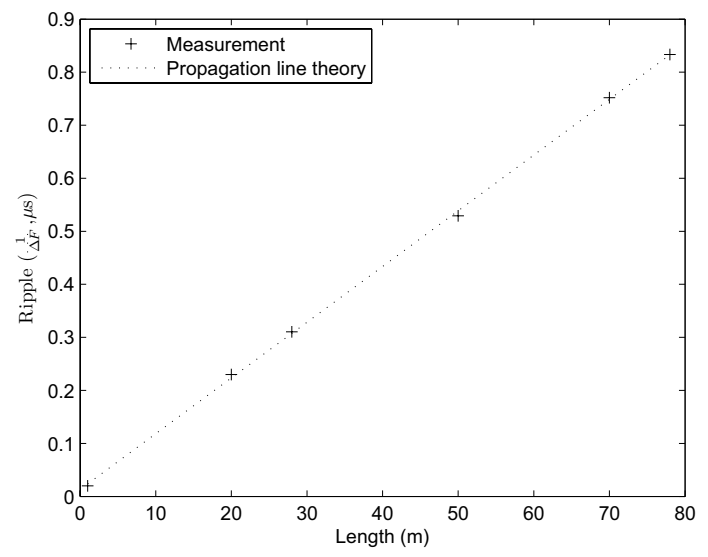

Figure 12. Ripple ratio as a function of the cable length.

impedance mismatch. Measurement of the frequency ripple value in Fig. 5 and Fig. 7 also verifies equation (2).

\section{INFLUENCE OF COMMUTATION TECHNOLOGY}

In section III and section IV, we have shown that the zero-crossing commutation $\left(t_{z c i}\right)$ is the least noisy situation. From now on, the $t_{z c i}$ will therefore be used. In order to do so, the mechanical thermostat radiator is replaced by an electronic radiator. Its commutation is based on a triac and a zero-crossing detection. Moreover, this kind of radiator accounts for $71 \%$ of electrical heaters in residential houses sold in 1998 in France (AERE Study "Chauffage électrique en France"). Since the end of 2006, this type of radiator is recommended by the thermal regulation "RT 2005" as it provides a better energy efficiency (Source: Thermor ${ }^{6}, \mathrm{ADEME}^{7}$ ).

Figure 13 compares the PSD of the mechanical commutation w.r.t. the PSD of the electronic commutation. Even though these two curves are obtained using a 30meter cable at $t_{z c i}$ and for the same electrical consumption $(500 \mathrm{~W})$, the curves are not merged. The thermal switch commutation is about $15 \mathrm{~dB}$ noisier than the triac

\footnotetext{
${ }^{6}$ Thermor: International company on white and grey goods.

${ }^{7}$ ADEME: French Environment and Energy Management Agency.
}

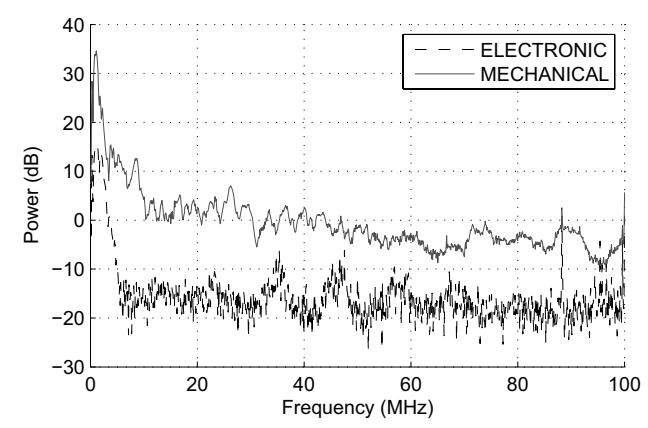

Figure 13. Commutation technology comparison at $t_{z c i}$ and for 30meter cable.

one. This could be explained firstly by the technology differences between the electronic and the mechanical heating load. Secondly, for practical wiring reasons, the commutation circuit is not in the same place. Fig. 14 presents the commutation configuration of an electronic radiator. It is to be compared with fig. 2. These two wirings are identical at low frequencies, but may exhibit different behavior at higher ones. Finally, the commutation technology used in the commutation tool is different. Further investigation is neccessary to fully understand the influence of all these parameters.

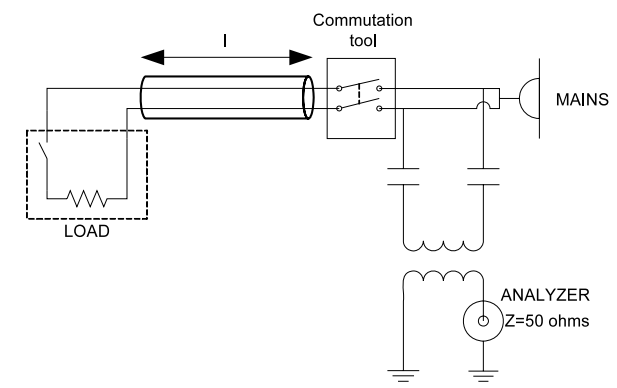

Figure 14. Analysis method for the electronic load commutation.

Considering the temporal signals (figures 15 and 16), the disturbance duration is reduced to one OFDM-symbol. The pulse amplitude is lower for an electronic thermostat radiator than for a mechanical one. The scale factor between the two pulse magnitudes explains the almost constant $16 \mathrm{~dB}$ difference observed between the two spectrum curves shown on Fig. 13.

In order to overcome the uncertainties due to the commutation system and heating technology, the rest of the study will use the most favourable case, i.e. a triac commutation system synchronized with the zero-crossing. We now turn to assessing the importance of the load value.

\section{INFLUENCE OF THE ELECTRONIC RADIATOR LOAD VALUE}

The commutation load at $t_{z c i}$ fixes the background noise level (III) irrespective of the length (IV). The last parameter to study is the effect of load value on the commutation. Fig. 17 shows the comparison between 


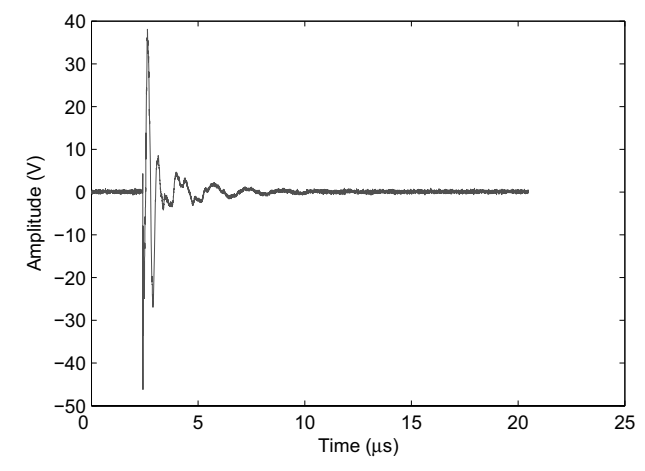

Figure 15. Commutation signal of a mechanical thermostat radiator.

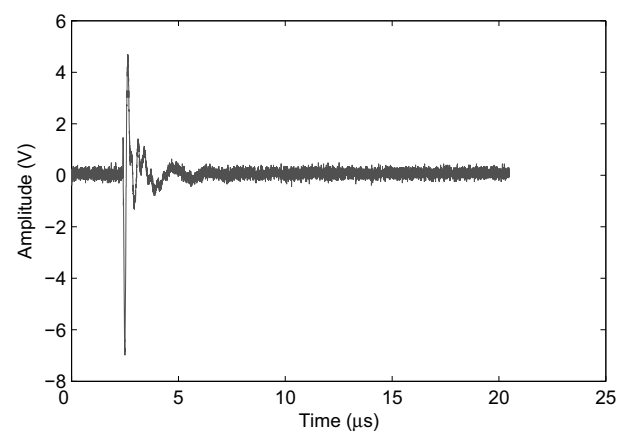

Figure 16. Commutation signal of an electronic thermostat radiator.

$500 \mathrm{~W}, 1000 \mathrm{~W}$ and $1500 \mathrm{~W}$ electronic radiators in the same product range of the same brand.

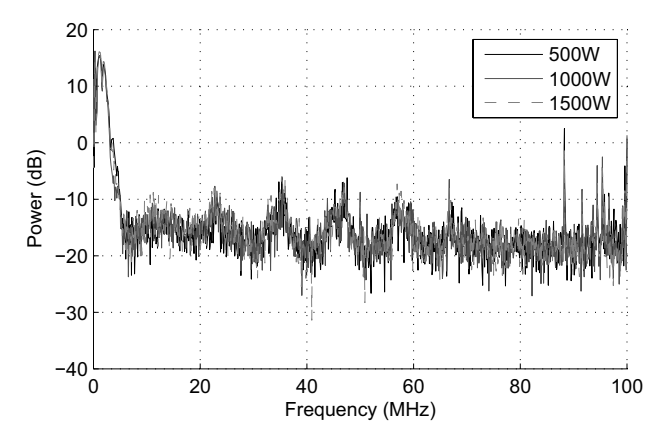

Figure 17. Load comparison at $t_{z c i}$ and for 30-meter cable.

All the curves of Fig. 17 are superimposed. This highlights the fact that for the same commutation system and the same heating load technology, the impulse response does not change. It can therefore be concluded that the noise generated is independent of the electrical power consumption value, i.e. the impedance at the mains frequency $(50 \mathrm{~Hz})$.

The noise floor of the measurement setup is about $27 \mathrm{~dB}$. This means that, considering the zoom on Fig. 18, frequencies up to $5 \mathrm{MHz}$ are concerned by the impulse noise.

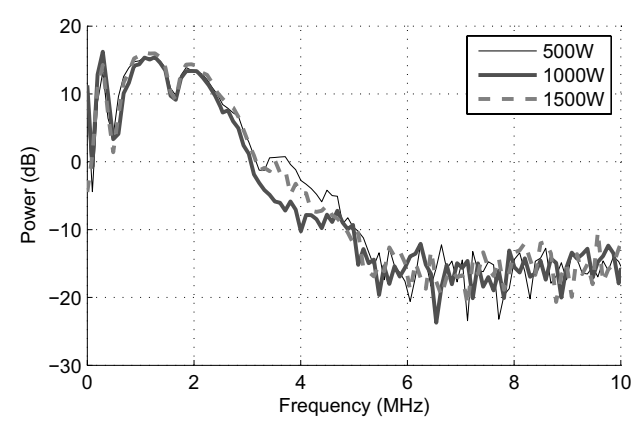

Figure 18. Zoom on the load comparison at $t_{z c i}$ and for 30-meter cable.

\section{CONCLUSION}

In this study, we have shown that the noise generated by asynchronous aperiodic impulse sources can be easily and significantly reduced. Indeed, the SNR, in a $40.96 \mu \mathrm{s}$ typical Homeplug AV OFDM symbol duration, can be improved by up to $15 \mathrm{~dB}$ simply by controlling the commutation instant of a resistive load. In this way, the asynchronous noise is made synchronous: the pulses are always located at the zero-crossing instant. In that case, the data rate is increased, and the synchronization sequence can be less corrupted.

Moreover, we have shown that the heating load technology, the position of the commutation circuit and the commutation system may influence the impulse noise power generated by about $16 \mathrm{~dB}$. Further study is necessary to investigate the role of each parameter involved in the $16 \mathrm{~dB}$ difference.

\section{ACKNOWLEDGMENT}

This work has been carried out in the framework of the French competitiveness cluster Science and Systems of Electrical Energy $\left(S^{2} E^{2}\right)$ - SESAME GEDELOC under contract $\mathrm{n}^{o}$ 2005-4020-06A-066.

\section{REFERENCES}

[1] "Homeplug av specifications," 2005, homeplug Powerline Alliance.

[2] T. C. Banwell and S. Galli, "A new approach to the modeling of the transfer function of the power line channel," in ISPLC, 2001.

[3] D. Anastasiadou and T. Antonakopoulos, "An experiment setup for characterizing the residential power grid variable behavior," in ISPLC, 2002.

[4] M. Zimmerman, "An analysis of the broadband noise scenario in power-line network," in ISPLC, 2000.

[5] E. Liu, Y. Gao, O. Bilal, and T. Korhonen, "Broaband characterization of indoor powerline channel," in ISPLC, 2004.

[6] M. H. L. Chan and R. W. Donaldson, "Amplitude, width, and interarrival distributions for noise impulses on intrabuilding powerline communication networks," IEEE Trans. Electromagnetic Compatibility, vol. 31, no. 3, 1989.

[7] H. Phillips, "Development of a statistical model for powerline communication channels," in ISPLC, 2000.

[8] Y. Hirayama, H. Okada, T. Yamazato, and M. Katayama, "Noise analysis on wide-band plc with high sampling rate and long observation time," in ISPLC, 2003. 
[9] M. Katayama, T. Yamazato, and H. Okada, "Linear predictive detection for power line communications impaired by colored noise," p. 12, 2007.

[10] G. Avril, F. Moulin, A. Zeddam, M. Tlich, and F. Nouvel, "Impulsive noise detection on masked carriers," in ISPLC, 2008.

[11] C. Assimakopoulos and F. N. Pavlidou, "Measurements and modeling of in-house power lines installation for broadband communications," in ISPLC, 2001.

[12] K. Dostert, Power-line comunications. New Jersey: Prentice Hall, 2001.

[13] Cpld coolrunner 2 xc2c256 datasheet. Http://www.xilinx.com/support/documentation/ data_sheets/ds094.pdf.

[14] Gage compuscope 12400 specifications. Http://www.gageapplied.com/Products/PDF/compuScope_12400.pdf.

[15] T. Esmailian, F. Kschischang, and P. Gulak, "Characteristics of in-building power lines at high frequencies and their channel capacity," in ISPLC, 2000.

[16] Gage compugen 4300 specifications. Http://www.gageapplied.com/Products/PDF/CG4300-4302.pdf.

[17] Opa2674 datasheet. Http://focus.ti.com/lit/ds/symlink/ opa2674.pdf.

Vincent Guillet was born in Gien, France on 12 November 1982. He received his MS degree in Electronics Signals and Microsystems from the University of Orléans, France, in 2006. $\mathrm{He}$ is currently a Ph.D. candidate at the Prisme Institute, University of Orléans, (Polytech'Orléans), France. His research interests include channel characterization, topologies and power line connected devices influences.

Guy Lamarque received his Ph.D. degree in engineering science from the University of Orléans, France, in 1992. His dissertation presents a method that improves in situ apparent ground resistivity measurement from spectral analysis of the magnetotelluric field components. This algorithm has been implemented in real time. In 1993, he joined an engineering school (Polytech'Orléans) where in 2005, was appointed head of the electronics department. $\mathrm{He}$ is currently working at the Prisme Institute, University of Orléans, France. His research interests focus on signal processing and its applications including real time implementation considerations.

Philippe Ravier was born in Chambéry, France on 22 February 1969. He received his $\mathrm{Ph}$. D. degree in engineering science, specializing in signal, image and speech processing, from the National Polytechnic Institute in Grenoble (France) in July 1998. Since 1999, he has been an assistant professor at the Ecole Polytechnique of the University of Orleans (Polytech'Orléans), France. His research deals with wavelets for detection purposes and time - frequency analysis in various application areas (underwater acoustics, electrophysiological signals and radioastronomy).

Christophe Léger is a full professor at the Prisme Institute of the University of Orléans, France. From the university of Orlans, he obtained a MS in electronics in "Signal and Image processing, Real-Time Systems" in 1990, and received a Ph.D. degree in Engineering Sciences in 1993. Christophe Léger's primary research interests concern signal and image processing applied to biomedicine, including spatio-temporal interpolation, Fourier analysis, deformable dynamic models and data registration. 